\title{
Esophageal ulceration mimicking malignancy in a patient with severe kyphoscoliosis
}

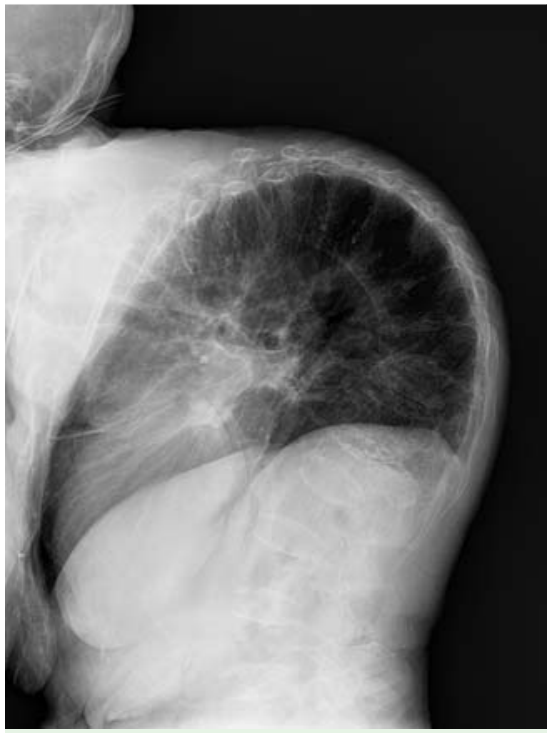

Fig. 1 Lateral chest radiograph with massive kyphosis, vertebral fractures, and demineralization of the skeleton.

Untreated severe kyphoscoliosis is rarely observed nowadays. In affected patients dislocation of inner organs with functional impairment may occur $[1,2]$. We present the unusual case of a patient with severe kyphoscoliosis who developed extensive esophageal ulceration.

An 83-year-old female presented with a 3week history of dysphagia, odynophagia, and nocturnal food regurgitation. She reported weight loss of $5 \mathrm{~kg}$ during the previous 3 weeks. Physical examination revealed severe kyphoscoliosis, which was additionally documented by chest radiography ( Fig. 1). Upper gastrointestinal endoscopy was performed and a huge, irregular mass was detected in the upper part of the esophagus, mimicking a malignant tumor ( Fig. 2). After the detritus had been removed, a large circumferential ulcer was visible ( Fig. 3). Biopsy material obtained from the lesion showed chronic unspecific ulceration with no signs of malignancy ( $\bullet$ Fig. 4). Adverse effects of oral medication were ruled out by careful interrogation of the patient, and mechanical ulceration due to alimentary bolus obstruction was taken as the most probable cause.

Parenteral nutrition was started with careful initiation of oral nutrition after 1 week; the patient was also instructed on appro-

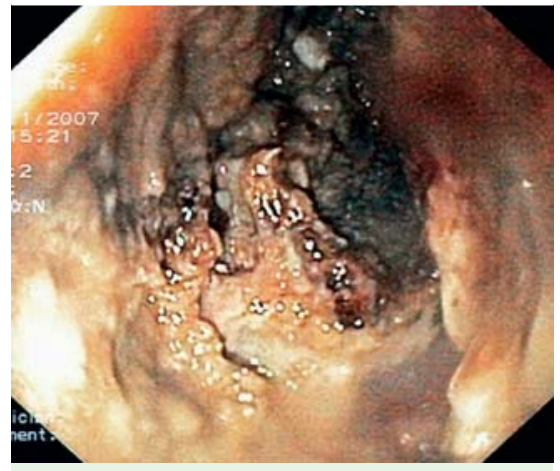

Fig. 2 Large, irregular mass in the upper part of the esophagus.

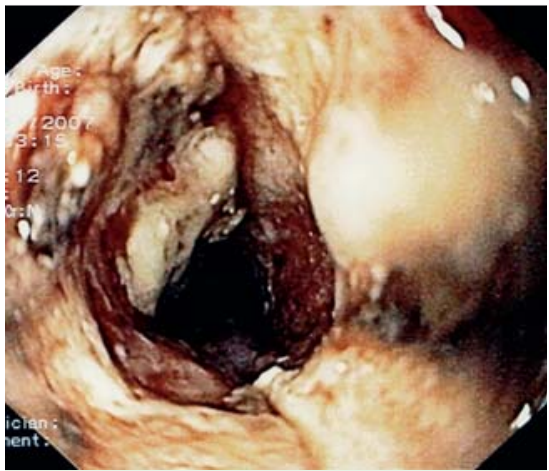

Fig. 3 After removal of detritus, a large circumferential ulcer is visible in the upper part of the esophagus.

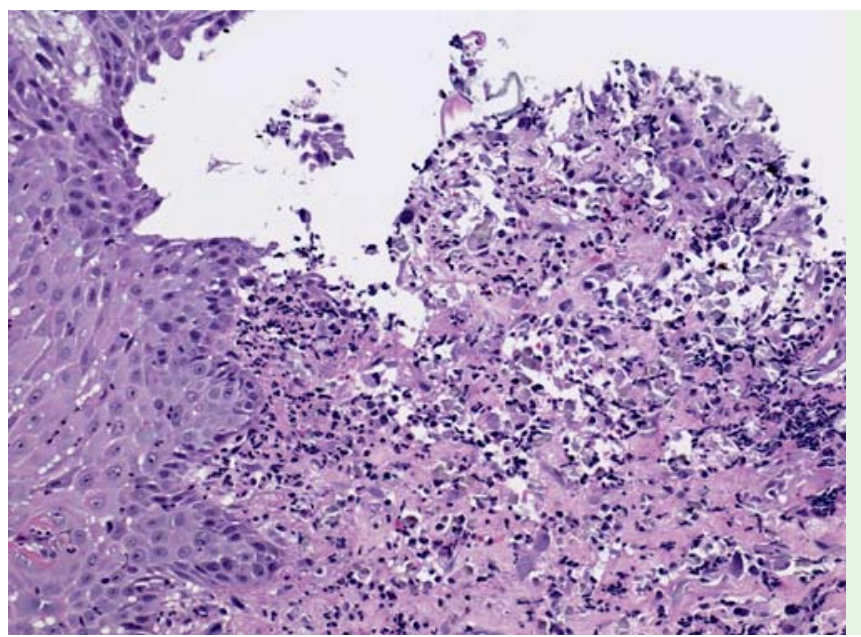

Fig. 4 Histology from the border of the ulcer with regenerating squamous epithelium and granulation tissue.

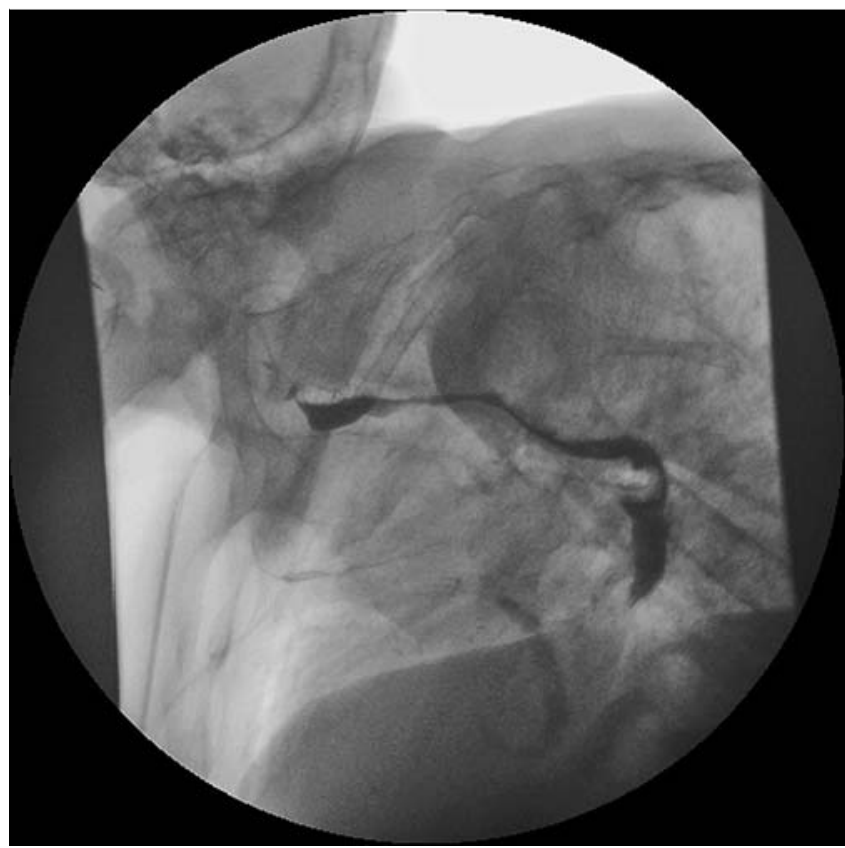

Fig. 5 Dynamic fluoroscopy in lateral projection illustrates pronounced dislocation of the esophagus. 
priate eating habits. Follow-up endoscopy 6 weeks after discharge revealed complete resolution of the esophageal ulcer. Dynamic fluoroscopy with contrast medium confirmed pronounced dislocation of the esophagus ( Fig. 5). Currently, 2 years later, the patient is doing well; she does not need artificial nutrition and body weight remains constant.

This case illustrates that kyphoscoliosis may severely impair esophageal function and may cause ulceration independent of drug history. It is well documented that several drugs commonly administered in patients with osteoporosis and/or kyphoscoliosis, for example oral bisphosphonates, may cause severe esophageal damage $[3,4]$. Although the esophageal transit of film-coated tablets appears to be normal in patients with kyphosis [5], we suggest that oral administration of drugs with known gastrointestinal side effects should be performed with caution in such patients and oral bisphosphonates should be completely avoided.

\section{Competing interests: None}

Endoscopy_UCTN_Code_CCL_1AB_2AC_3AZ
P. P. Rainer ${ }^{1}$, A. Eherer ${ }^{1}$, C. Langner ${ }^{2}$, W. B. Graninger ${ }^{1}$, C. Spreizer ${ }^{3}$, K. Weber $^{1}$

1 Department of Internal Medicine, Medical University of Graz, Graz, Austria

2 Department of Pathology, Medical University of Graz, Graz, Austria

3 Department of General Radiology, Medical University of Graz, Graz, Austria

\section{References}

1 Goyal N, Narlawar R, Garrett A. Kyphosis, a rare cause of dysphagia. Age Ageing 2005; 34: 521-522

2 Yamaguchi T, Sugimoto T, Yamauchi $M$ et al. Multiple vertebral fractures are associated with refractory reflux esophagitis in postmenopausal women. J Bone Miner Metab 2005; 23 : $36-40$

3 Hokama A, Ihama $Y$, Nakamoto $M$ et al. Esophagitis dissecans superficialis associated with bisphosphonates. Endoscopy 2007; 39 (Suppl 1): E91

4 Terashima T, Hiramatsu K, Shimatani A et al. An esophageal ulcer mimicking advanced esophageal cancer in a patient on alendronate sodium treatment for osteoporosis. Endoscopy 2006; 38 (Suppl 2): E37

5 Perkins AC, Frier M, Blackshaw PE et al. Esophageal transit of the weekly filmcoated risedronate (Actonel) placebo tablet in subjects with Kyphosis. Int J Pharm 2006; 311: $20-25$
Bibliography

DOI 10.1055/s-0029-1243991

Endoscopy 2010; 42: E119-E120

(c) Georg Thieme Verlag KG Stuttgart · New York · ISSN 0013-726X

\section{Corresponding author}

P. P. Rainer, MD

Department of Internal Medicine Medical University of Graz Auenbruggerplatz 15 8036 Graz Austria

Fax: +43-316-3853733

peter.rainer@medunigraz.at 